Gut, 1972, 13, 566-570

\title{
In-situ and invasive carcinoma of the colon in patients with ulcerative colitis
}

\author{
D. J. EVANS AND D. J. POLLOCK
}

From the Departments of Pathology, Royal Postgraduate Medical School and London Hospital

SUMMARY Four cases are described in which ulcerative colitis was complicated by carcinoma and in which the extent of the accompanying in-situ carcinoma (precancer) was determined.

The extent of the in-situ carcinoma was very variable and in all cases the rectum was spared in whole or part. Search for in-situ carcinoma in rectal biopsies will fail to indicate the development of malignancy in some patients with ulcerative colitis. Alternative methods of cancer detection in this group are discussed.

It is now well established that patients with ulcerative colitis have an increased risk of developing carcinoma of the colon (Rosenqvist, Öhrling, Lagercrantz, and Edling, 1959; Edwards and Truelove, 1964; Goldgraber and Kirsner, 1964).

These carcinomas are difficult to recognize radiologically, and the patients may be relatively asymptomatic until the tumour is extensive. Clearly, a method of early diagnosis would be of value in these cases.

Morson and Pang (1967) suggested that rectal biopsy repeated annually is a valuable method of recognizing patients who are developing large bowel cancer. They based this on the finding that 'precancerous change', which they equated with in-situ carcinoma, was often extensive in ulcerative colitis, and was most frequent in the left side of the colon and in the rectum. They were not able to assess the extent of precancer in their material and we felt it of interest to record our experience of four cases in which such an assessment was possible.

Received for publication 15 May 1972.

\section{Case Reports}

These cases were encountered over a period of two years at the London Hospital and at the Hammersmith Hospital. All the patients had severe attacks of diarrhoea, with blood and mucus in the stools. All had been diagnosed as ulcerative colitics, and all had had biopsies and barium enemas confirming this diagnosis. Further clinical details are shown in the Table. The histopathological findings are briefly summarized.

In the description the term 'in-situ carcinoma' is preferred to that of 'precancer' used equivalently by Morson and Pang. To substantiate the diagnosis the epithelial cells must show cytological features of malignancy. These are increased nucleo-cytoplasmic ratio, enlarged nuclei, irregular nuclear shape, abnormal chromatin pattern, prominent nucleoli, and abnormal mitoses (Fig. 2 and Fig. 6). In association with these cytological features the mucosa shows an irregular glandular pattern and sometimes has a microvillous or micropolypoid

\begin{tabular}{|c|c|c|c|c|c|c|}
\hline Case & Sex & $\begin{array}{l}\text { Age at } \\
\text { Onset } \\
(y r)\end{array}$ & $\begin{array}{l}\text { Age at } \\
\text { Operation }\end{array}$ & Operation & Indication for Operation & Outcome \\
\hline 1 & $\mathbf{F}$ & 31 & 59 & Total proctocolectomy & $\begin{array}{l}\text { Carcinoma found } \\
\text { clinically }\end{array}$ & Died of metastases \\
\hline 2 & $\mathbf{M}$ & 11 & 41 & Total proctocolectomy & $\begin{array}{l}\text { Carcinoma found } \\
\text { clinically }\end{array}$ & Died of metastases \\
\hline 3 & $\mathbf{F}$ & 15 & 25 & $\begin{array}{l}\text { Partial colectomy, } \\
\text { ileorectal anastomosis }\end{array}$ & $\begin{array}{l}\text { Failure of medical } \\
\text { treatment }\end{array}$ & $\begin{array}{l}\text { Well; negative } \\
\text { rectal biopsies }\end{array}$ \\
\hline 4 & $\mathbf{M}$ & 12 & 24 & Total proctocolectomy & $\begin{array}{l}\text { Failure of medical } \\
\text { treatment }\end{array}$ & Well \\
\hline
\end{tabular}

Table Clinical details of four cases of ulcerative colitis and carcinoma 
appearance (Fig. 1 and Fig. 6) and the epithelial cells show loss of mucin production and an apparent stratification of their nuclei.

\section{CASE 1}

The colon was $82 \mathrm{~cm}$ long and ahaustral. The mucosa showed extensive ulceration with many pseudopolyps. A sessile carcinoma, $4 \times 2.5 \mathrm{~cm}$, was present $4 \mathrm{~cm}$ from the ano-rectal junction. Microscopically this was moderately well differentiated and infiltrated but did not penetrate the muscle coat. A second sessile tumour, $6.5 \times 5.4 \mathrm{~cm}$, in the mid-transverse colon was less well differentiated microscopically and penetrated the muscle to the serosal surface. The entire colonic mucosa was blocked and representative sections were cut. These showed chronic ulcerative colitis with no evidence of in-situ carcinoma, except in a very limited area a few millimetres square near the rectal carcinoma.

\section{CASE 2}

The colon was grossly shortened $(52 \mathrm{~cm})$. It was ahaustral, and showed a benign stricture $8 \mathrm{~cm}$ long in mid-transverse colon. A centrally ulcerated sessile carcinoma, $6 \mathrm{~cm}$ in diameter, centred $13 \mathrm{~cm}$ above the ano-rectal junction, was present. This had penetrated the muscle coat and two nearby lymph nodes were found to contain metastatic carcinoma. The remaining colonic mucosa showed evidence of chronic ulcerative colitis. Microscopy confirmed the ulcerative colitis and showed that the carcinoma was a well differentiated adeno- carcinoma. No in-situ carcinoma was found in representative sections cut from blocks of the entire colon.

CASE 3

The partial colectomy specimen was a $40 \mathrm{~cm}$ length of colon and caecum, with partially preserved haustration in the caecum. The mucosal appearance was remarkable with innumerable, very tiny micropolypi, giving it a velvety appearance. A single mucosal plaque, $1 \mathrm{~cm}$ in diameter, in the caecum lacked this appearance. Microscopically the whole colonic mucosa, as far as the lower cut end, showed evidence of carcinoma in situ with abnormalities of gland pattern (Fig. 1) and cytological features of malignancy (Fig. 2). The plaque in the caecum was a carcinoma which invaded the muscle coat (Fig. 3).

In view of the histology further operation was advised but refused by the patient. Review of a rectal biopsy taken three weeks before colectomy showed no evidence of in-situ carcinoma and two subsequent rectal biopsies have shown only active ulcerative colitis (Fig. 4).

\section{CASE 4}

The proctocolectomy specimen was $74 \mathrm{~cm}$ long and showed marked loss of haustration. The mucosa of the rectum and sigmoid showed areas of macroscopic ulceration and patches of relatively normal mucosa. Near the recto-sigmoid junction there were areas of mucosa with a velvety appear-

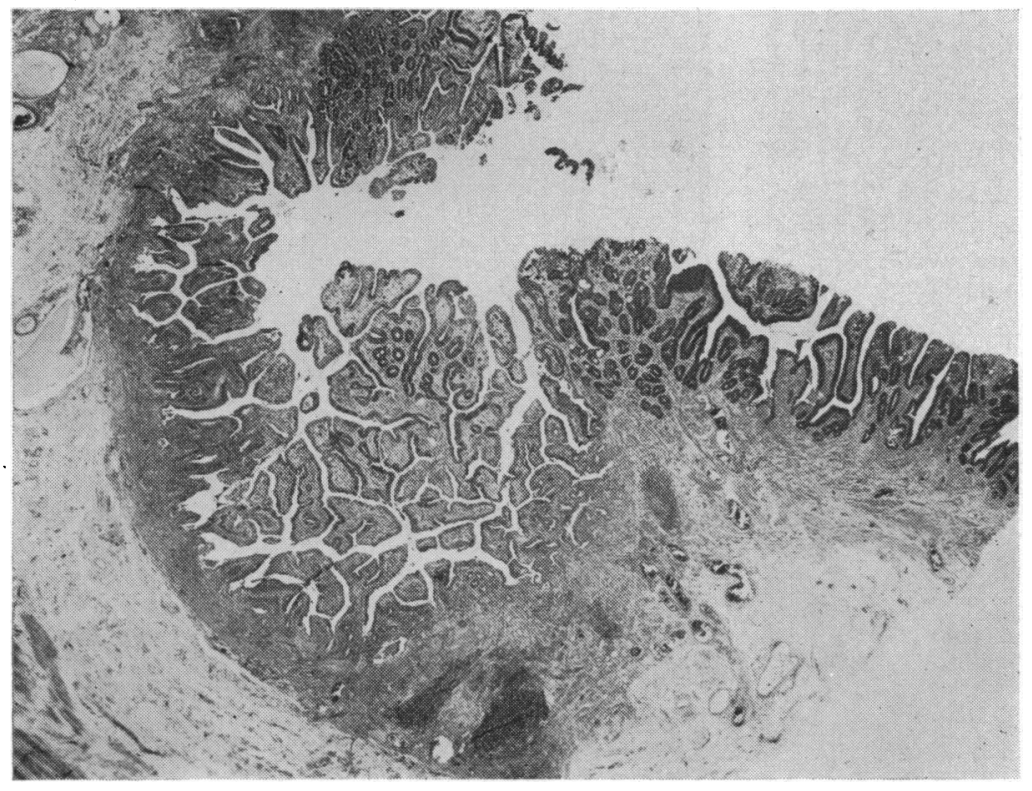

Fig. 1 Colonic mucosa from case 3 showing a total loss of normal mucosal pattern. There is an irregular microvillous and micropolypoid configuration and the glands are very variable in size and shape. $H \& E \times 15$. 

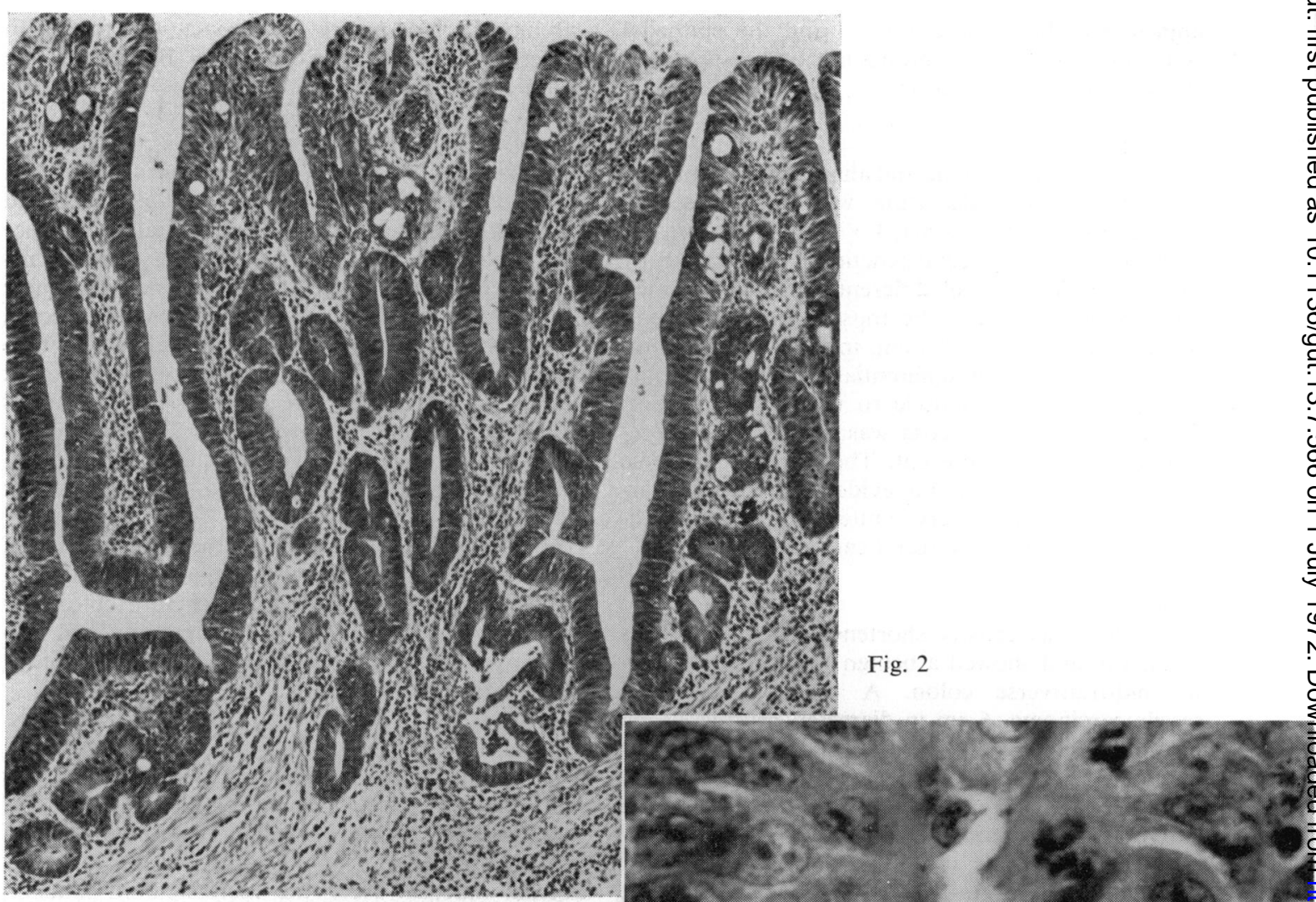

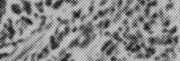
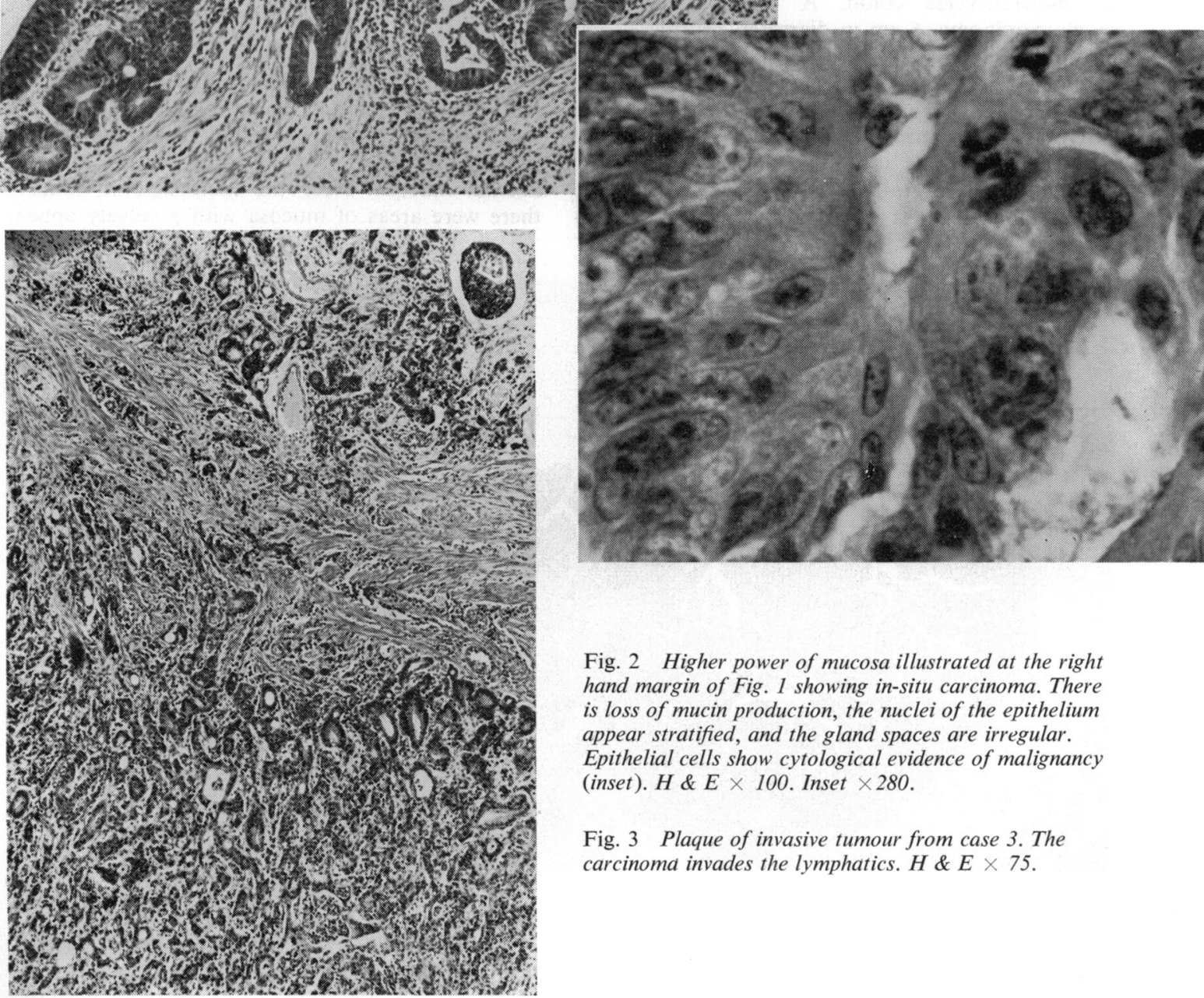

Fig. 2 Higher power of mucosa illustrated at the right hand margin of Fig. 1 showing in-situ carcinoma. There is loss of mucin production, the nuclei of the epithelium appear stratified, and the gland spaces are irregular. Epithelial cells show cytological evidence of malignancy (inset). $H \& E \times 100$. Inset $\times 280$.

Fig. 3 Plaque of invasive tumour from case 3. The carcinoma invades the lymphatics. $H \& E \times 75$. 


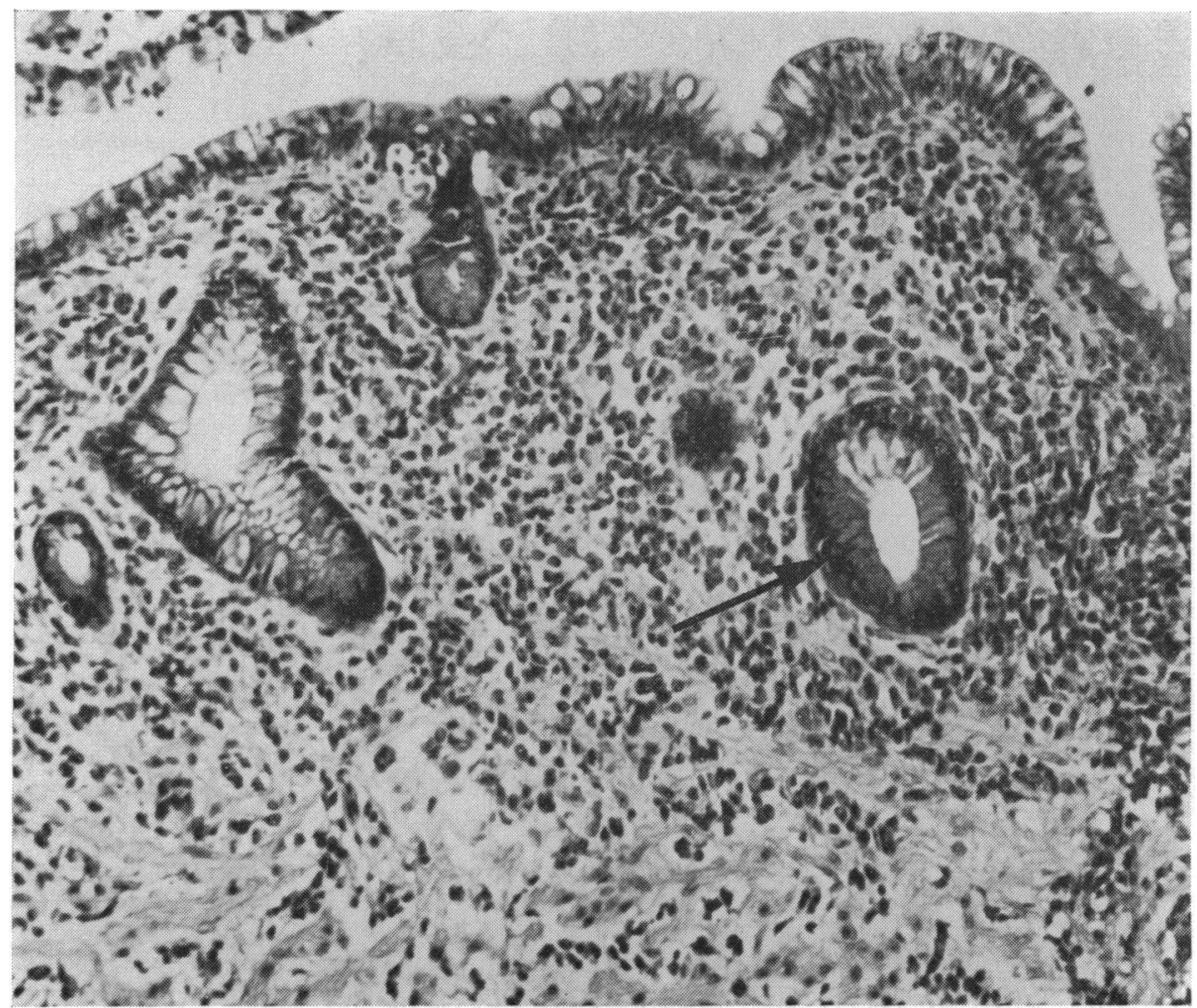

Fig. 4 Rectal biopsy showing inflamed mucosa with Paneth cell metaplasia (arrow). There is no evidence of in-situ carcinoma. $H \& E \times 250$.

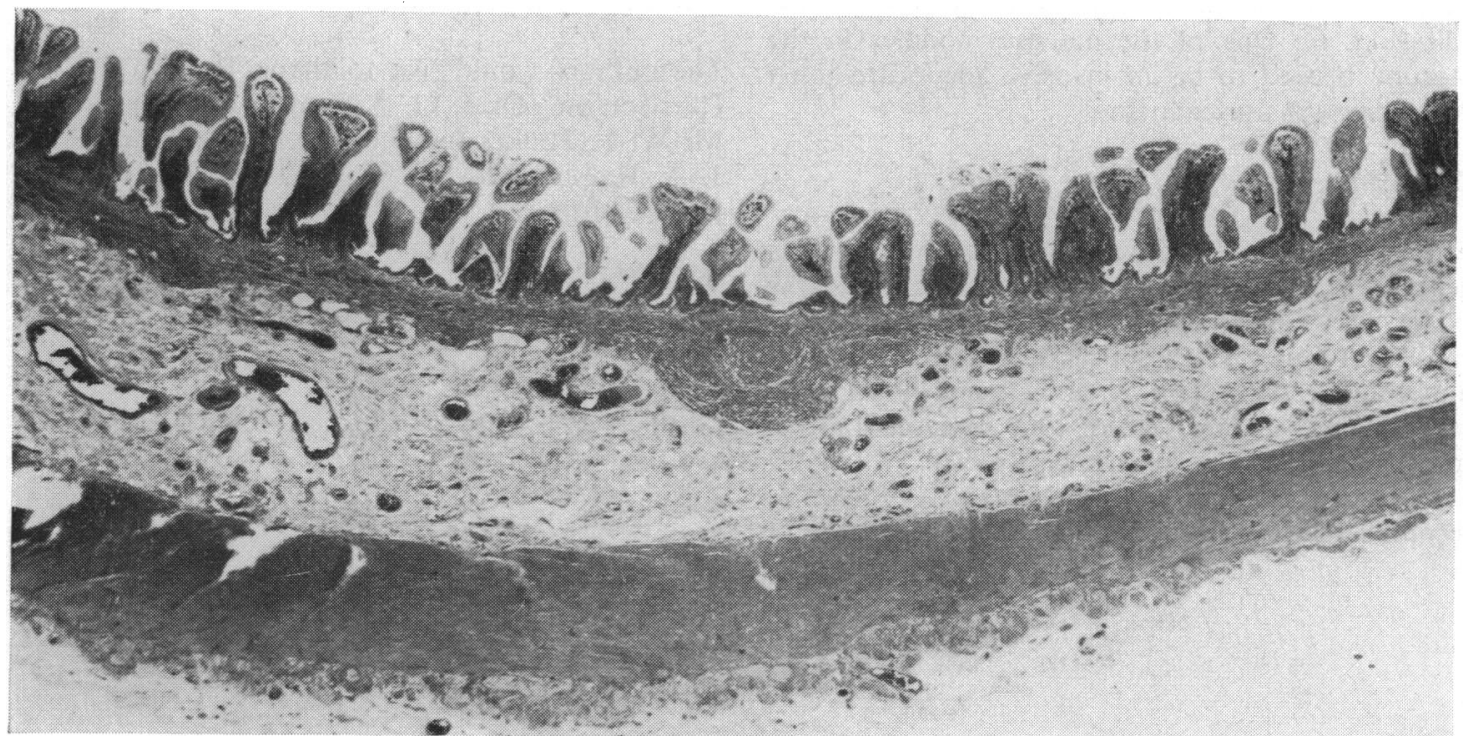

Fig. 5 Villous pattern of mucosa in descending colon (case 4). $H \& E \times 15$. 


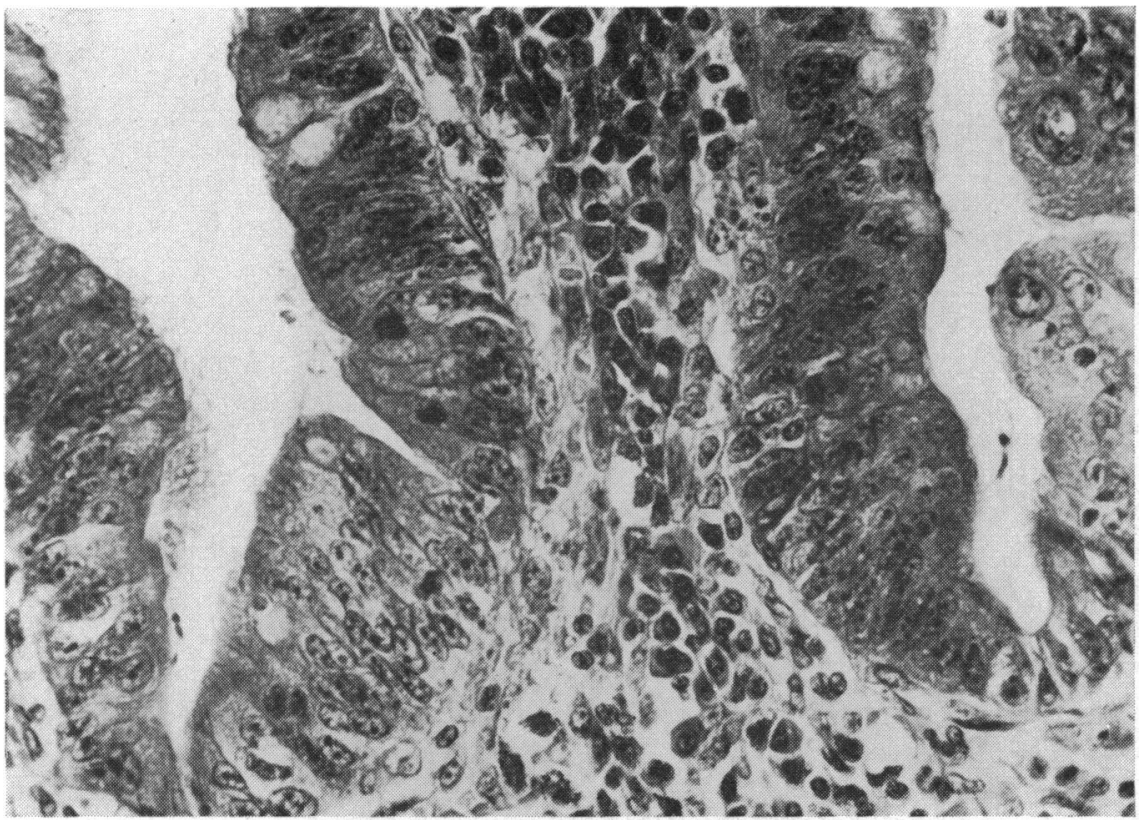

Fig. 6 Detail of base of 'villus' from descending colon (case 4) showing in-situ carcinoma. There is reduced mucin production and apparent stratification of nuclei which are enlarged, irregular and show prominent nucleoli and abnormal chromatin. $H \& E \times 400$.

ance, and the mucosa in the whole of the caecum and the rest of the colon had a similar aspect. Three sessile mucosal nodules, maximum diameter $1 \mathrm{~cm}$, were present in the caecum. Microscopically, the rectum and sigmoid showed only chronic active ulcerative colitis. Throughout the rest of the colon the mucosa showed short villi (Fig. 5) covered by an epithelium showing cytological evidence of malignancy which was most clear cut at the bases of the villi (Fig. 6). One of the mucosal nodules in the caecum proved to be an invasive adenocarcinoma infiltrating the muscularis.

\section{Discussion}

From these cases it is apparent that when carcinoma develops in patients with ulcerative colitis, the extent of accompanying in-situ carcinoma is very variable. It may be absent or restricted in distribution as in cases 1 and 2 , or very extensive as in cases 3 and 4 . The rectum and sigmoid may be spared in whole or in part in either case.

In the present state of knowledge it is difficult to recommend an ideal method of cancer detection for the ulcerative colitic. Certainly, regular proctoscopy and biopsy will detect a proportion of cases of developing malignancy, but the limitations of this procedure must be recognized. It is likely that screening for carcino-embryonic antigen in the blood, faeces, colonic washings, or exfoliated cells will prove more reliable methods and these are currently under evaluation (Freed and Taylor, 1972; Evans and Morris, in preparation).

The authors would like to thank Professor C. V. Harrison and Dr J. G. Azzopardi for their advice, Mr W. F. Hinkes for photomicrography, and Miss J. A. Ralph and Miss M. I. Dougherty for secretarial assistance.

\section{References}

Edwards, F. C., and Truelove, S. C. (1964). The course and prognosis of ulcerative colitis. IV. Carcinoma of the colon. Gut, 5, 15-22.

Freed, D. L. J., and Taylor, G. (1972). Carcinoembryonic antigen in faeces. Brit. med. J., 1, 85-87.

Goldgraber, M. B., and Kirsner, J. B. (1964). Carcinoma of the colon in ulcerative colitis. Cancer (Philad.), 17, 657-665.

Morson, B. C., and Pang, L. S. C. (1967). Rectal biopsy as an aid to cancer control in ulcerative colitis. Gut, 8, 423-434.

Rosenqvist, H., Öhrling, H., Lagercrantz, R., and Edling, N. (1959). Ulcerative colitis and carcinoma coli. Lancet, 1, 906-908. 